\title{
ON THE USE
}

OF THE

\section{LACTUCA VIROSA,}

IN

\section{HOOPING-COUGH.}

BX T. GUMPRECHT, M.D.

PFYSTCIAN IN HAMBURG AND HOLFRATH IN SAXE-COBURG.

COMMUNICATED BY

WILLIAM LAWRENCE, EsQ.

Read December 6th, 1814.

THOUGH the number of remedies recommended for the hooping-cough is already very considerable, yet I believe I may be allowed to increase it with one, which, by experience, I have found to be extremely efficacious.

My observation of the good effects of the extrac. tum lactucae virosae in the dyspnœa of hydrothorax, and in spasmodic asthma in general, led me to conjecture that this medicine might also be useful in the hooping-cough, as this disease seems to be a spasmodic affection of the diaphragm and of the 
organs of respiration, and often resists the best methods of treatment.

It has been with reason observed, that hitherto, in the treatment of this disease, the stadium cathar. rale has not been sufficiently distinguished from the stadium convulsivum. The first stage is inflammatory, and ought to be opposed only with mild antiphlogistic, diaphoretic, and demulcent medicines. If, neglecting these precautions, irritating, antispasmodic medicines be .employed at this period, experience has frequently shewn that they may produce very bad effects. It is only when this stage is past, and the stadium convulsivum has taken its place, that it is proper, according to the age and bodily constitution of the patient, to apply the above-mentioned means.

As the herba lactucæ virosæ does not grow in all places, and is sometimes confounded with the herba lactucæ scariolæ, great care must be taken that the extractum lactucæ virosæ (which is made from the inspissated juice of the herba lactucæ virosæ) be genuine and properly prepared. In the neighbourhood of Hamburg, for example', this plant does not grow, and the apothecaries of this place procured the extract from Hildesheim*.

* The mode of preparing the extract is stated in Collin's Observ. circa morbos, Part 6, Vol. XIV. and Murray's Apparalus Medicaminum, Vol. I. p. 170.

VOL. VI.

$\mathbf{R} \mathbf{R}$ 
Some months ago, I communicated my obsern vations on the beneficial effects of this medicine, to one of our most employed and esteemed physicians, Dr. Chaufepié, who, as well as several other physicians here, has used it with great success: On this occasion I received the following letter.

\section{(TRANSLATION.)}

c6 I return you many thanks for the friendly " communication of your observations on the ad"s vantages of the extractum lactucæ virosæ in " cases of the hooping-cough. The present epi" demic, though mild, and of a good sort, and " very seldom accompanied with dangerous symp"s toms, has furnished opportunities sufficient, to " make experiments with regard to the application 's and the advantages of this method of cure. I " immediately communicated your observations to "several other physicians here, and we have all " found this medicine to be a valuable and pow"6 erful specific in the above-mentioned disease. " Its efficacy is great in the second stage, or the ". convulsive period of the disease. To children of " two years, I gave it three times a day, at first: « in doses of half a grain, with sugar alone, united \$6 with any of the other medicines usually employa " ed. At this age I have not administered it in "c doses of more than three-fourths of a grain. The is coughing fits soon became more rare, and more "gentle, the expectoration took place with less " effort, and in general without vomiting; and the 
$\approx$ spasmódic affection in the region of the dia«c phragm apparently gave' way. Upon the whole, s6 this medicine seems, in a short time, to give the " cough a different character, and considerably to "c diminish its duration."

Dr. Hempel and Dr. Jacobsen of this city have also, on my recommendation, employed this medicine in the spasmodic stage of the hooping-cough, and acknowledged its beneficial effects. "With regard to the modus operandi of this remedy, it is well known that the cuticular system is much connected with the urinary organs and those of respiration; and as the lactuca virosa has a considerable operation on the skin, is a powerful anodyne, and a strong diuretic, it may, for these reasons, be of great utility in the: hooping-cough. Among the antispasmodics furnished by the vegetable kingdom, it will be difficult to find one which unites in itself the same qualities, in so remarkable a degree as this medicine.

That the lactuca virosa must act as a specific on the organs of respiration, is rendered probable by the benefit derived from it in spasmodic affections of the breast, and in the dyspncea of hydrothorax : for when, particularly in the last-mentioned instance, all diuretic and antispasmodic means are found to fail, an alleviation of the dangerous symptoms, if not a cure of the disease, may almost always be experienced from the use of the lactuca virosa, 
I shall now present to the Society, from my own journal, two cases in which a cure of the hooping-cough was effected by the medicine in question.

\section{CASE I.}

J. K. a child 15 months old, had been for eight days troubled with a cough, of which several children in the neighbourhood, with whom this child had been in contact, had died. The fits were at first merely of the catarrhal kind; but five days after the commencement, the following symptoms appeared. When the fit came on, the child endeavoured to support itself by stretching out its arms; it became red in the face, and tears started into its eyes; during the coughing the child was seized with a suffocating affection; its breath stopped, and the by-standers imagined it was about to be choaked; the belly was spasmodically contracted; the characteristic whistling tone of the hooping-cough in drawing in the breath appeared, and the fit ended with vomiting. Similar fits took place five or six times during the day, and several in the night. Towards evening an increase of heat in the skin, and thirst were perceived. Hitherto the parents had used several prescriptions, which I had before written for attacks in the chest, in the same family; and as these failed of success, I was 
called in on the 28th of June, 1812. I found that the child suffered much; the coughing fits were very frequent, and the fever had increased. I ordered a draught composed of aqua fœeniculi, gum arabic, and vinum antimonii Huxhami*.

June 30. The coughing fits were still the same. I ordered the same medicine to be continued, substituting only spiritus Mindereri, in lieu of the vin. ant. Huxh.

July 2. As the fits had rather increased than diminished, with however a diminution of the fever, and thirst, I ordered one of the following powders to be given every two hours, viz. R. extr. lact. vir. gr. iv. sacch. lact. 5jj. Div. in X. partes æquales.

July 4. The coughing and suffocating fits were become less frequent, the vomiting less violent, and sometimes it did not take place at all. The child became more lively, and had no fever. I ordered at the same intervals one of the following powders, viz. R. extr. lact. vir. gr. vj. sacch. lact. 3jj. Div. in xi. partes æquales.

July 6. The coughing fits recurred less frequently, were considerably diminished, as to intenseness, and the vomiting had ceased. The suffocating fits no longer appeared during the day,

* The old antimonial wine of the London College. 
but sometimes returned in the night, though not so violently as before. The child passed much urine, was cheerful, and had some appetite. I ordered every two and a half hours one of the following powders, viz. R. extr. lact. vir. gr. vij. sacch. lact. 3 jj. Div. in x. partes æquales.

July 8. The cough had nearly again taken the form of a catarrhal cough. In the morning the child still coughed at times, and in the night still more, but without any spasmodic attack. I ordered the prescription of the 6th to be continued.

July 13. During the whole of this day the child coughed but little, and seldom. In the nighttime the cough returned, from time to time, with. some violence, but without suffocation and vomiting. I continued the last-mentioned powders, and in the evening before the child went to sleep; caused a powder and half to be administered.

July 15. The cough had now completely assumed the form of a catarrhal cough in the last stage. I ordered a mixture aq. fl. naph. (aurant.) extr. myrrh. extr. cort. per. and eleosacch. foenic.

\section{CASE II.}

On the 31st of December, 1812, I was called to attend a girl of four years of age, who bad been 
for seven days affected with the following symptoms. In the day-time she had several fits of coughing, attended with a threatening suffocation; and the characteristic crying sound of the hooping-cough, ending with vomiting. In the evening she had heat and thirst. As this was only the first stage of the illness, I ordered a mixture of 'gum arabic; oxym. simpl. aq. fœnic. and a little vin. ant. Huxh.

Jan. 1, 1813. The fits had not assumed a better appearance, but on the contrary became worse. The suffocating attacks returned more frequently, the heat and thirst in the evening continuing. The mother of the child informed me, that it had been for some time troubled with worms; and on this account I ordered a purge of pulv. rad. jalap. and calomel, and continued the above mixture.

Jan. 5. The coughing fits were increased, and in the evening a fit lasted nearly nine minutes. The suffocating attacks were violent, and the vomiting frequent. In the evening there was some fever and thirst. The purgative had operated eight times, and expelled a quantity of ascarides. I now ordered one of the following powders every two hours, in chamomile tea.

R. extr. lact. viros. gr. vj. sacch. alb. 3ij. Div. in xi. partes æquales.

- Jan. 7. Hitherto I could pereeive no change 
in the symptoms, and therefore ordered $\frac{3}{4}$ ths of a grain of extr. lact. vir. with sugar every two hours. In the morning, on account of the worms, I ordered a second purge.

Jan. 9. The coughing fits had decreased a little in violence, and the patient brought up much tough slime, after the attacks. In the evening she had a little fever. She had had several foetid stools, but no appearance of worms, and there was great want of appetite. I ordered one grain of the extract every two hours, and provided the proper diet, which the parents, poor people, had been hitherto obliged to neglect.

Jan. 11. Though the coughing fits still continued as violent, yet they returned seldomer. On the preceding day, the cough had been accompanied with bleeding at the nose. The child passed much urine.

Jan. 12. The coughing fits are now considerably diminished in intenseness and frequency, the patient having had only one fit yesterday, and two in the night. Much urine, and an easy expectoration. Medicine as before.

Jan. 15. On the 13th she had three attacks of the cough, but without vomiting, and of shorter duration than before. Much urine, expectoration easy. On the 14th a little coughing without vomit- 
ing, during the day; the night quiet. The powders continued in smaller doses.

Jan. 28. The cough had in the mean time assumed the form of a catarrhal cough. I gave a jelly of Iceland moss, with bitter extract to complete the cure. 